\title{
PROGRAMA ESPECIAL DE FORMAÇÃO PEDAGÓGICA, UMA REFLEXÃO HISTÓRICA
}

\author{
PROGRAMA ESPECIAL DE FORMACIÓN PEDAGÓGICA, UNA REFLEXIÓN \\ HISTÓRICA
}

SPECIAL PEDAGOGICAL EDUCATION PROGRAM, A HISTORICAL REFLECTION

\author{
Maria Isa Pinheiro Cardoso GONÇALVES ${ }^{1}$ \\ Isabelle de Luna Alencar NORONHA ${ }^{2}$ \\ Zuleide Fernandes QUEIROZ ${ }^{3}$
}

RESUMO: A formação docente é uma temática sempre em evidência, sob os mais diferentes enfoques, em estudos no meio educacional. Para este artigo, tomaremos, de forma não excludente, as dimensões política, histórica e pedagógica da formação, enfatizando a que é construída pelo Programa Especial de Formação Pedagógica no âmbito da Universidade Regional do Cariri - URCA. Neste sentido o texto está organizado da seguinte forma: inicialmente, apresentamos uma abordagem histórica do citado programa e sua inserção (1998-2019) na referida IES, procurando identificar os impactos que o mesmo causa na região do Cariri cearense. A seguir refletimos sobre a formação dos sujeitos (discentes do programa) à luz dos objetivos aos quais o Programa Especial de Formação Pedagógica se propõe e por meio de suas próprias palavras em depoimentos colhidos por questionários eletrônicos aplicados entre os meses de outubro e novembro de 2020. O texto traz resultados de uma pesquisa etnográfica assim caracterizada em virtude do envolvimento das autoras com o objeto de investigação. Por fim, defendemos a permanência do Programa Especial de Formação Pedagógica em solo caririense.

PALAVRAS-CHAVE: Educação. Programa especial. Formação docente.

RESUMEN: La formación del profesorado es un tema que siempre se evidencia, bajo los más diversos enfoques, en los estudios en el ámbito educativo. Para este artículo, tomaremos, de manera no excluyente, las dimensiones políticas, históricas y pedagógicas de la formación, en evidencia la que construye el Programa Especial de Formación Pedagógica en el ámbito de la Universidad Regional de Cariri - URCA. En este sentido, el texto se organiza de la siguiente manera, inicialmente, presentamos un enfoque histórico del mencionado programa y su inserción (1998-2019) en las referidas IES, tratamos de identificar los impactos que ocasiona en la región Cariri de Ceará. A continuación, reflejamos la formación

\footnotetext{
${ }^{1}$ Universidade Regional do Cariri (URCA), Crato - CE - Brasil. Professora Adjunta do Departamento de Educação. Mestre em Educação (URCA). ORCID: https://orcid.org/0000-0002-1726-3494. E-mail: mariaisagoncalves@yahoo.com.br

${ }^{2}$ Universidade Regional do Cariri (URCA), Crato - CE - Brasil. Professora Adjunta do Departamento de Educação. Doutorado em Educação (UFPB). ORCID: https://orcid.org/0000-0003-0529-0951. E-mail: isabelle.luna@urca.br

${ }^{3}$ Universidade Regional do Cariri (URCA), Crato - CE - Brasil. Professora Permanente do Programa de Mestrado Profissional em Educação (PMPEDU/URCA). Doutorado em Educação (UFC). ORCID: https://orcid.org/0000-0003-3174-4750 E-mail: zuleidefqueiroz@gmail.com
} 
de los sujetos (alumnos del programa) a la luz de los objetivos a los que se propone el Programa Especial de Formación Pedagógica y a través de sus propias palabras en declaraciones recogidas por cuestionarios electrónicos aplicados entre los meses de octubre $y$ noviembre de 2020. El texto aporta resultados de una investigación etnográfica caracterizada así por la implicación de los autores con el objeto de investigación. Finalmente, defendemos la permanencia del Programa Especial de Formación Pedagógica en suelo Caririense.

PALABRAS CLAVE: Educación. Programa especial. Formación docente.

ABSTRACT: Teacher education is a theme that is always in evidence, under the most different approaches, in studies in the educational environment. For this article, we will take, in a non-exclusive way, the political, historical and pedagogical dimensions of education, in evidence the one that is built by the Special Pedagogical Education Program within the scope of the Regional University of Cariri - URCA. In this sense, the text is organized as follows, initially, we present a historical approach of the mentioned program and its insertion (19982019) in the referred IES, we try to identify the impacts that it causes in the Cariri region of Ceará. Next, we reflect the education of the subjects (students of the program) in the light of the objectives to which the Special Pedagogical Education Program proposes and through its own words in statements collected by electronic questionnaires applied between the months of October and November 2020. The text brings results of an ethnographic research thus characterized by virtue of the authors' involvement with the object of investigation. Finally, we defend the permanence of the Special Pedagogical Education Program in Cariri soil.

KEYWORDS: Education. Special program. Teacher education.

\section{Introdução}

O presente artigo objetiva abordar historicamente o Programa Especial de Formação Pedagógica com ênfase na sua implantação e presença na Universidade Regional do Cariri (URCA) desde os anos de 1998, quando ele foi encampado em meio a uma crescente demanda por formação docente, em atendimento para além dos anseios sociais, às políticas neoliberais.

À época, a recém regulamentada Lei de Diretrizes e Bases da Educação Nacional 9394/1996 passa a exigir (art. 62) a formação superior para professores do ensino básico e a contínua valorização dos profissionais da educação (art. 67). Somando-se isto ao quadro de numerosos professores leigos em atuação na educação brasileira em todos os seus níveis de ensino e aos impactos causados pelo premente crescimento das redes públicas e privadas do Ensino Fundamental, ainda que este fosse para cumprir metas de erradicação do analfabetismo firmadas com organismos internacionais, é certo afirmar que muitos docentes 
recorreram a alternativas de formação, ou de complementação destas, e, que nem sempre tais formações possuíam qualidade pedagógica (FLORENCIO; FIALHO; ALMEIDA, 2017).

Como objetivos específicos buscamos entender por que um curso que deveria ter caráter emergencial continuaria, como continua, após mais de vinte anos de sua implantação, como este se organiza pedagogicamente para a formação docente, o que move os sujeitos que dele participam, quem são esses sujeitos e quais os impactos sociais que podem ser observados por meio de sua existência no cenário educacional ocupado pela URCA.

É importante frisar que na busca que empreendemos na literatura educacional para a construção da pesquisa que ora se apresenta, encontramos parcos estudos que abordam esta temática, embora este seja um programa de abrangência nacional, oferecido por várias IES públicas e particulares. Em geral os artigos citam as origens do chamado "esquema $3+1$ ", basicamente de forma negativa e enfatizando os infortúnios que este modelo de formação causou à história da educação no Brasil (FIALHO; CARVALHO; NASCIMENTO, 2021). Não encontramos nenhuma abordagem positiva que buscasse descortinar os fazeres formativos de um Programa Especial de Formação Pedagógica, refletindo-o criticamente, à luz de sua proposta pedagógica e do olhar dos seus sujeitos, tal como este estudo se propõe a fazer.

Trata-se de uma pesquisa etnográfica porque as autoras investigam o próprio ambiente de trabalho, traduz-se, aqui, uma releitura de uma dissertação de mestrado de Gonçalves (2020). Conforme Gil (2019, p. 37), “o problema do subjetivismo talvez seja o mais crítico da pesquisa etnográfica", outrossim, o próprio autor considera que ela apresenta uma série de vantagens em relação a outras metodologias e "seus resultados tendem a ser mais fidedignos". Ainda segundo esse autor, para a definição de uma amostra qualitativa para este tipo de pesquisa, pode ser utilizado o "julgamento do próprio pesquisador". Nesse caso, a escolha dos discentes para responder ao questionário se efetivou de forma aleatória, privilegiando os anos de 2016 e 2018, não desconsiderando os demais. No entanto, a abrangência temporal do trabalho deu-se a partir do momento em que o Programa Especial de Formação Pedagógica (vulgo Esquema I) foi instituído na URCA, em julho/1998.

O texto faz uma rápida incursão histórica nos anos de 1930 para buscar as origens do Programa Especial de Formação Pedagógica, traz ao debate sua imersão na URCA, sob outra perspectiva, mas não totalmente desvencilhado do passado. Reflete os fazeres do programa à luz de sua proposta pedagógica e dá voz dos sujeitos que o realizam, assim, chega às questões finais, que indicam ser este um campo ainda carente de investigações científicas. 


\section{Esquema 3 + 1, a formação sob o enfoque histórico}

No campo educacional, os anos de 1930 apresentaram férteis mudanças, com a influência dos renovadores e a política de Getúlio Vargas que, via educação, pretendia imprimir no país uma identidade nacional, o que levaria a uma pretensa unidade em um país mergulhado em um processo de disputas políticas, econômicas e sociais (MENDES; FIALHO; MACHADO, 2019). As forças em disputa apenas concordavam em um ponto, a crença de que somente a educação poderia salvar o país do caos, da miséria e fazê-lo progredir. É importante ressaltar que essa crença fora alimentada ao longo da década de 1920 a 1930, quando várias reformas educacionais eclodiram por diversos estados da federação, constituindo-se, conforme Biccas (2011, p. 173): “[...] num marco para a educação pois a partir delas buscaram-se novos instrumentos teóricos, pedagógicos e metodológicos para orientar e intervir na sociedade sem desprezar, porém, ações anteriores e posteriores a elas".

Foi a partir do Decreto $N^{0} 21.241$, de 4 de abril de 1932, que foram estabelecidas as disposições sobre o ensino secundário, a formação e a nomeação de professores para esse nível de ensino e, posteriormente, com a implantação da Faculdade de Filosofia Ciências e Letras (FFCL), locus de formação desse profissional e o diploma de habilitado passou a ser uma exigência para a nomeação dos docentes para as séries do ensino secundário. "A primeira dessas faculdades surgiu com a Fundação da Universidade de São Paulo, em 1934" (SOUZA, 2008, p. 150).

Com a Fundação da Universidade de São Paulo em 1938 houve segundo Brzezinski (1996, p. 39), uma incorporação à FFCL da Escola de Professores do Instituto de Educação, e é, neste contexto, que se efetiva a promulgação do Decreto-Lei n. 1.190 , de 04 de abril de 1939, que, desse modo, regulamenta o sistema de formação de professores que passa a vigorar no país até os anos de 1960:

Segundo o padrão federal eram necessários três anos para cursar o conteúdo específico da área de saber e mais um para o curso de didática. Os bacharéis em ciências sociais, filosofia, história natural, geografia e história, química, física e matemática, letras e pedagogia, acrescentavam mais um curso à sua formação para se tornarem licenciados. [...] Esse sistema da formação de professores secundários perdurou por 23 anos e passou para a história dos estudos pedagógicos em nível superior como 'esquema $3+$ um' (BRZEZINSKI, 1996, p. 43-44). 
Neste modelo de formação os alunos cursavam, nos três primeiros anos, as disciplinas próprias do bacharelado, e após a conclusão recebiam o título de bacharel. Aos bacharéis que conclú́ssem com êxito mais um ano do "Curso de Didática" seria conferido um diploma de licenciado no grupo de disciplinas que compunham o currículo dos seus respectivos bacharelados. O bacharelado tinha a duração de três anos e o Curso de Didática, 1 ano, daí o nome Esquema 3+1. Essa estrutura de formação assim permaneceu até a aprovação da primeira Lei de Diretrizes e Bases da Educação Nacional, LDB, $\mathrm{n}^{\circ}$. 4.024, de 20 de dezembro de 1961, que vigorou por um curto período de tempo, sendo revogada pela Lei 5.540, de 1968, e, Lei 5.672, de 1971, ambas promulgadas em período ditatorial, a primeira reformou o ensino universitário e a segunda o ensino de $1^{\circ}$ e $2^{\circ}$ graus.

É com a redemocratização do país que mais uma vez vozes antagônicas concordam em um ponto: é preciso investir em educação. É promulgada a atual LDB 9.394, de 1996, que em parte atende aos anseios de formação para a cidadania e democratização social, e em parte atende a interesses mercadológicos que se revelam em práticas neoliberais. Percebe-se, no entanto, que o histórico descaso com a formação docente, e com a educação de forma geral, desenhou um quadro de evidentes contrastes sociais, infelizmente ainda não superados, como o analfabetismo. Brzezinski (2008, p. 171-172) denuncia que após dez anos da publicação da LDB 9394/1996, os problemas no campo educacional ainda são graves, “os professores leigos continuam presentes, principalmente nas regiões norte e nordeste, são necessários mais de 230 mil professores no ensino médio [...] para atender ao número de estudantes hoje existentes na rede pública”. O Anuário Brasileiro da Educação Básica (2019, p. 102) divulga que em 2018 $37,8 \%$ dos professores das séries finais do Ensino Fundamental ( $5^{\circ}$ ao $9^{\circ}$ ano) não tinham a formação adequada; no Ensino Médio esse índice é de 29,2\%.

E importante assinalar que a partir da nova legislação houve uma procura por parte dos profissionais do magistério por cursos de formação docente ou de complementação pedagógica, e que muitos programas surgiram desde então; apenas para citar, dentre outros: cursos de Licenciatura Plena em Ensino Fundamental; Programa Magister; e os cursos oriundos do Plano Nacional de Formação de Professores para a Educação Básica (PARFOR), todos estes encampados pela URCA. Nesse âmbito ressurge também o Programa Especial de Formação Pedagógica (correspondente ao antigo Esquema $3+1$ ), que foi definido pelo Parecer $\mathrm{n}^{\circ}$ 4, de 1997, do Conselho Nacional de Educação (CNE) com as seguintes características, 
i) Têm caráter emergencial. Por isso são tratados como programas e não cursos;

ii) Destinam-se a portadores de diplomas como nível superior;

iii) Devem ser oferecidos no âmbito de cursos que tenham direta vinculação com a habilitação pretendida;

iv) Cabe à instituição verificar a compatibilidade entre a formação do candidato e a disciplina objeto da pretendida habilitação (CARNEIRO, 2010, p. 442).

Apenas fazendo uma necessária ressalva, ainda antes da atual LDB, a Portaria $\mathrm{n}^{\circ} 339$ de 07 de agosto de 1970 do Ministério da Educação consagrou as expressões Esquema I e Esquema II, sendo este último dedicado aos conteúdos de disciplinas específicas da área técnica. Isto nos leva à compreensão de que a história sempre fez uso formações especiais para suprir lacunas de profissionais devidamente habilitados no ensino básico e profissional, o que indica a perenidade de tais ações em legislações e efetivas práticas educacionais.

\section{O Curso Especial de Formação Pedagógica na URCA}

A Universidade Regional do Cariri - URCA, fundada em 07 de março de 1987, tem sua sede na cidade de Crato, região sul do Ceará. Sua área de abrangência alcança mais de 100 municípios entre os estados do Ceará, Piauí, Pernambuco e Paraíba.

Dentre as muitas atividades desenvolvidas pela URCA, é preciso salientar que dos 19 cursos de graduação ofertados, 12 são de habilitação para o magistério, e por vezes eles se replicam em variados campi (nas cidades de Crato, Iguatu, Campos Sales e Missão Velha), o que implica que a URCA é responsável pela maioria do corpo docente que atua em seu território.

Na URCA, o Programa Especial de Formação Pedagógica surgiu no ano de 1998, como uma solicitação da Secretaria de Educação do Estado do Ceará - SEDUC-CE, considerando a existência de profissionais bacharéis e tecnólogos exercendo ou disponíveis à docência sem a adequada formação. Inicialmente esteve atrelado à Universidade Estadual do Ceará - UECE, situada na capital do estado, a $560 \mathrm{~km}$ de distância do Crato.

Havia, como já enfatizamos anteriormente, a necessidade de formar professores rapidamente, tanto em atendimento às demandas da LDB 9394/1996 como às políticas externas provenientes do Banco Mundial e de outros organismos internacionais e ao crescente número de alunos nas escolas, posto que o país tardiamente estava universalizando o seu ensino. 
Receber e encampar um Programa Especial de Formação Pedagógica nessa conjuntura exigiu/exige a definição de claros parâmetros de aportes teóricos e práticos sobre qual profissional formar, a serviço de qual construção social e uma constante reflexão a fim de tornar esses professores aptos a lidarem com as dimensões técnicas, políticas e humanas do ato educativo, fortalecerem as dimensões libertadoras e transformadoras inerentes à educação (VASCONCELOS; FIALHO; LOPES, 2018). Desafio aceito, a URCA firmou parceria com a UECE e assinou um convênio em 1998 que perdurou até o ano de 2006.1, quando a URCA elaborou, reconheceu e implantou o seu projeto próprio do Esquema I, dando continuidade ao trabalho de formação iniciado até a presente data.

A melhoria de condições do trabalho docente, ainda que de forma tímida, intensificou e estimulou a entrada no magistério de bacharéis e tecnólogos que passam a buscar a necessária habilitação para o magistério.

O que deveria ser, portanto, um Programa de oferta contingencial, tem se mostrado ainda necessário após mais de 20 anos de sua implantação na URCA. A sua oferta atende a um público especial que continua existindo, sobretudo, nas áreas de Matemática, Física e Biologia, e em menor escala se manifesta nas demais áreas, como Química e Letras, todas consideradas pela consideradas pela CAPES como "áreas prioritárias" em virtude, dentre outros fatores, da falta de profissionais aptos para o magistério.

Durante os 21 anos de funcionamento do Esquema I na URCA é preciso identificar que em parceria com a UECE (1998-2006) foram formadas 8 turmas que habilitaram 392 alunos(as) em diversas áreas da docência do Ensino Fundamental e Médio (matemática, português, história, geografia, física, inglês, química, biologia). Em 2006, quando a URCA assume o seu próprio projeto de turma, a prioridade recai nas áreas de Matemática, Biologia e Física, que apresentaram as demandas mais significativas. Assim, no período de 2007 a 2018 , 288 alunos foram habilitados para o exercício do Magistério por meio do Programa Especial de Formação Pedagógica da URCA. Ao todo, de 1998.2 até 2018.1 são 680 professores/alunos habilitados, oriundos de 40 municípios: 36 do Ceará, 03 de Pernambuco e 01 da Paraíba.

A última turma, em funcionamento, iniciou com 34 alunos matriculados e atualmente conta com 32 alunos cursando, com previsão para ser concluída em 2021.1 (por não terem concluído esses cursistas não constam nas estatísticas atuais). Aproveitamos este último dado para fazer a ressalva de que praticamente não houve/há evasão nas turmas ofertadas, cuja taxa média de desistência é de 12,1\%, problema que, nas licenciaturas, de forma geral, ainda é bastante desafiador. Pesquisas revelam que a taxa de evasão nas licenciaturas já chegou a 
atingir índices maiores que 50\% (GAIOSO, 2005); inferimos que isso pode estar atrelado à qualidade pedagógica do curso ofertado, mas também ao caráter diferenciado do seu público.

\section{Formação docente, campo de disputas, resistências e construção de saberes}

Inicialmente, é preciso dizer o Curso Especial de Formação Pedagógica da URCA (Esquema I) habilita bacharéis e/ou tecnólogos à docência, e que tais bacharéis, em sua maioria, já estão nas escolas, informalmente, substituindo docentes em suas faltas, ou formalmente, em cargos administrativos, ou ainda, em serviços voluntários.

O público é formado por biomédicos, enfermeiros, biólogos, tecnólogos da construção civil, engenheiros, advogados, dentre outros profissionais, que inclusive apresentam cursos de mestrado e doutorado em suas áreas específicas e, embora a maioria exerça as suas profissões de origem, buscam ampliar conhecimentos sobre a docência para também exercê-la de forma plena.

Neste sentido, os docentes que ministram as disciplinas no Esquema I da URCA também são rigorosamente escolhidos de acordo com a formação e atuação didáticopedagógica que exercem. É um curso de caráter privado, dentro de uma IES pública, cujos custos cobrados objetivam a sua própria manutenção e preveem a matrícula de alunos com a emissão de bolsas integrais seguindo critérios estabelecidos.

A efetivação do currículo segue as determinações legais e de acordo com o Projeto Pedagógico em vigor à época da pesquisa. Possui carga-horária de $615 \mathrm{~h}$, todas presenciais, inclusive ultrapassando em 75 horas o mínimo prescrito na legislação. O projeto Pedagógico do curso deverá sofrer alterações em virtude da Resolução do CNE - CP No 2, de 20 de dezembro de 2019. Organiza-se em três núcleos: contextual global (com as disciplinas pedagógicas), específicos (ênfase nas metodologias específicas) e o integrador.

O núcleo integrador se efetiva com a oferta de dois estágios, com 150 horas cada e distribuídos a partir do final do $1^{\circ}$ núcleo, o contextual. $\mathrm{O}$ estágio multidisciplinar profissionalizante, cursado por todos os alunos do programa, tem como objetivo o conhecimento do campo de trabalho dos professores: a escola, seus processos administrativos, pedagógicos e financeiros. O estágio de docência se efetiva na disciplina à qual o aluno será habilitado.

Zabala (1988) descreve como saberes da prática educativa os saberes conceituais e factuais, procedimentais e atitudinais, que são, fazendo uma analogia, as dimensões científicas, técnicas e humanas do ato educativo. Um clássico freireano (FREIRE, 1997) 
aborda "os saberes necessários à prática educativa" na perspectiva de uma educação que forme para a autonomia. Constamos pelo projeto pedagógico do curso e por nossa experiência que o Programa Especial de Formação Pedagógica da URCA objetiva estas citadas dimensões no seu contexto formativo. O profissional habilitado no Esquema I consegue perceber o que afirmamos? Como saber? Como isso se efetiva foi objeto de nossa investigação.

Os questionários, aplicados por meio do google forms, continham as seguintes questões: identificação; local de residência, motivos que o/a levaram a fazer o curso Esquema; citar os saberes adquiridos no curso; se houve mudança na vida profissional dos investigados após concluírem o Esquema I; como avaliam a experiência com o curso e o que mudariam no mesmo. Foram respondidos por 18 estudantes, cujos nomes serão preservados conforme ressaltamos no termo de consentimento para uso das respostas com fins acadêmicos. A escolha dos discentes para responder ao questionário se efetivou de forma aleatória, privilegiando os anos de 2016 e 2018, em virtude de nosso acesso aos mesmos. Conforme tratamos até aqui, a abrangência temporal do trabalho é partir do momento em que o Esquema foi instituído na URCA, em junho/1998, até a presente data. Possibilitou-se coletar a percepção dos professores, considerando suas subjetividades (FIALHO et al., 2020).

Neste sentido, a nossa amostra contou com 07 discentes de Juazeiro do Norte, 04 da cidade do Crato, 01 do Barro, 01 de Jardim, 01 da cidade de Exu, estado do Pernambuco, 02 de Barbalha, 01 de Nova Olinda e 01 de Altaneira. Dentre esses, há biólogos, tecnólogos de construção civil, administradores, contadores, economistas.

Com relação ao primeiro questionamento (as motivações para ingresso no curso), três afirmam que pensaram em uma forma de conseguir mais rapidamente a licenciatura; os demais citam desenvolvimento profissional, pessoal, aprendizagem de novas metodologias, indicação de ex-alunos, corpo docente e comprovada competência da URCA no campo da formação profissional de professores, enfim, conseguir aprender mais sobre o campo educacional.

A questão de conseguir mais rapidamente uma licenciatura está imbricada na questão do emprego, e pode indicar o magistério como campo profissional aberto, sem tantas exigências, em que é possível uma complementação de renda, sem o efetivo comprometimento com ele. A pesquisa demonstra, no entanto, que em maior número as respostas primaram pelo aprender/vivenciar a docência, e destacaram a experiência da URCA no âmbito da formação, o que demonstra comprometimento e afeto.

Vejamos alguns recortes das respostas (importante colocar que os discentes estão identificados por números): 
Conseguir uma outra graduação para trabalhar no magistério. (Discente 14).

A titulação possibilitar a participação em concurso público. (Discente 16).

No início tinha apenas o intuito de mais uma graduação, mais com o passar das aulas fiquei encantado com o formato do programa e vi uma nova oportunidade de carreira. (Discente 07).

A necessidade para o mercado de trabalho, mas também a necessidade de aprender metodologias para aplicar em sala de aula. (Discente 04).

Investimento na formação da carreira docente com a aquisição da licenciatura. (Discente 17).

Há, pois, uma estreita relação entre melhorar profissionalmente e atender ao mercado de trabalho cada vez mais restrito e excludente. Para tanto, não há muito tempo e recorre-se a uma "rápida" formação ou "formação aligeirada". Destacamos que anteriormente afirmamos que o Esquema I não se desvencilhou totalmente do antigo Esquema 3+1, do qual herdou a denominação, isto porque ambos recorrem a um ano de formação pedagógica como se os saberes da docência pudessem ser solidificados com isso, mais uma vez, em contextos diferenciados, atendendo à lógica do capital. Entendemos, porém, que não cabe às instituições de Ensino Superior ficarem alheias às políticas formativas, principalmente quando estas se tratam de leis e decretos, posto que sem o atendimento a isto não há funcionamento escolar. $\mathrm{O}$ que vale é ser resistência, e encontrar formas de se contrapor sem menosprezar o poder limitado, mas real, que a educação possui de formar para a autonomia. E essa resistência se efetiva, por vezes, na postura pedagógica que o professor assume, no cuidado com o ambiente em que a educação acontece, na literatura da qual este se apropria, nas formas de ser e fazer as práticas educativas em diálogo com as condições sócio-políticas em que a instituição escolar se encontra (BRANDENBURG; PEREIRA; FIALHO, 2019).

Perguntamos o que o Curso mudou na vida daqueles que o fizeram, e dentre as respostas, encontramos quatro bastante vagas: "complexidade" (Discente 10); "boa" (Discente 12), “ainda não" (Discente 12); "não" (Discente 16). O que pode indicar as limitações do mercado de trabalho, como afirma o depoimento a seguir:

Na prática não, mas mudou a visão de escola e educação. Vou pra sala de aula se for convocado no concurso que estou aguardando convocação. A experiência no curso foi ótima, sobretudo a parte do estágio onde pude vê na prática a profissão de professor. (Discente 04) 
Compreendemos, pois, que a motivação maior dos discentes é mesmo o mercado de trabalho, mas que o curso permite uma visão ampliada de educação, e isto pode se configurar como uma forma de resistência. Vejamos outras respostas:

Houve uma mudança considerada, pois os conhecimentos adquiridos ao longo do curso irão me proporcionar uma visão diferenciada do ensino de ciências além de abrir novos leques de oportunidades em novos campos do conhecimento até então desconhecido. (Discente 01).

Sim. Pude me aperfeiçoar bastante através da rica troca de experiência com os professores e colegas. A minha prática pedagógica hoje é outra, minha visão acerca da educação é mais próspera. (Discente 05).

Continuei como docente, mas pude ampliar as áreas de atuação. Experiência muito boa. Gostei do curso. (Discente 09).

Entendi mais minha missão enquanto professora e me senti mais segura e leve. Foi um laboratório de ensino fantástico. A troca de experiências entre bacharéis professores de diferentes idades, experiências e locação profissional (privado, estadual, municipal, desempregado) e niveis foi um enriquecedor laboratório. (Discente 11).

Se um dos valores do neoliberalismo é a competição e o individualismo, no curso eles trocam experiências e aprendem sobre cooperação. A ênfase na troca de experiências corrobora com o entendimento de que a educação não pode privilegiar apenas um de seus aspectos, mas trabalhar na perspectiva global, integral do ser. Tais saberes também aparecem direcionados em outras dimensões sociais em que os discentes já atuam ou que passam a atuar com o curso:

Através das técnicas adquiridas me potencializou como educador a ter um melhor suporte remoto aos meus clientes externos bem como o suporte técnico a colaboradores internos da empresa. (Discente 08).

Sim. A partir das disciplinas no curso comecei a trabalhar na área da educação especial. (Discente 14).

O Curso foi muito importante por permitir o desenvolvimento profissional no campo do magistério, a formação em Licenciatura na área da Física. A experiência foi essencial para a atuação como professor na Educação Básica e oportunidade para o investimento na continuação dos estudos. (Discente 17).

Neste sentido, o Programa de Formação Especial Pedagógica da URCA compreende a formação como um processo, que não termina com a graduação, seja ela bacharelado ou licenciatura, ela é contínua, acontece em momentos de estudos, de discussões, de leituras individuais e/ou coletivas, mesmo em meio a um sistema por vezes opressor. 
O Esquema I, como já foi dito, é um curso privado em uma IES pública, o que pode caracterizar que o público que o frequenta é privilegiado, mas não é assim, alguns o fazem com sacrifícios que se revelam em pagar transportes, mensalidades, alimentação, dentre outras despesas. Alguns alunos entram na cota de gratuidade permitida no curso. Isto para citar ou referenciar um outro descaso com a educação, a precariedade da formação docente, que advém do corte de verbas e da ausência de políticas que priorizem o ensino e a docência.

Lembramos que alguns discentes já são professores na prática, se aperfeiçoam e se habilitam com o curso, e passam a ter direitos legais. O sonho da maioria é ser aprovado em concurso público. Como o discente 07 , que descreveu como a sua vida mudou com o curso: "Sim, após dei aulas, palestras, e orientações matemáticas. A minha experiência foi maravilhosa conheci diversas pessoas de estados diferentes, cursos, o que me proporcionou um grande agregado de saberes".

Os saberes aos quais ele se refere continuarão em construção, em modificação. Se tomamos por empréstimo os saberes docentes relacionados por Tardif (2002, p. 63), veremos que as fontes de aquisição dos mesmos são inúmeras, da família, da escola, dos cursos, programas, livros, prática da docência, troca de experiências com os pares, dentre outras.

Continuaremos, no entanto, com Zabala para relacionarmos os saberes (conceituais/factuais, procedimentais e atitudinais) que os discentes afirmaram ter adquirido com o Esquema: a maioria das respostas abrangem os fazeres pedagógicos (rotina, planejamento, metodologias); consideremos interessante a transcrição de alguns:

Planejamento Educacional, Montagem de plano de aula, teorias do desenvolvimento (Piaget e Vygotsky). (Discente 01).

Didática de sala de aula, filosofias do ensino, fases do desenvolvimento da criança, práticas pedagógicas. Desenvolvimento pessoal, Responsabilidade social como um formador de opinião. (Discente 05).

A vivência do ensinar, método educacionais, a observância crítica entre as politicas educacionais e o "chão de giz", a humanização nos processos educacionais. (Discente 09).

As citações são textuais e mostram a abrangência de saberes adquiridos e recriados, e deixam ler que os objetivos do curso parecem estar sendo concretizados quando a reflexão do ato pedagógico é ampliada e está relacionada à condição de "ser e estar no mundo", como destacam Alves, Fialho e Lima (2018), em estudo sobre formação em pesquisa para professores da educação básica. 
Dentre estes, as aprendizagens práticas com a LIBRAS foram citadas por três vezes. É importante colocar que a URCA, como parte de suas políticas afirmativas, mantém um núcleo de Acessibilidade à Pessoa com Deficiência, desde março de 2016. As falas dos discentes em relação à disciplina de LIBRAS podem revelar a pouca evidência social desta linguagem, posto que se configuram num misto de admiração e encantamento:

Conhecimentos na área de educação especial, sobretudo com a disciplina LIBRAS; como se planejar pra uma aula; conhecimentos de didática; saberes relacionados ao comportamento do aluno; o papel do professor enquanto educador; teorias da aprendizagem. (Discente 15).

Obtive um conhecimento inicial em libras. Através da Sociologia da Educação tive a oportunidade de conhecer o pensamento dos principais pensadores da educação de acordo com o período ao qual vivenciaram, $e$ em razão dessa situação aprendi a duvidar do pensamento de qualquer estudioso. Obtive conhecimento básico de Filosofia da Educação, psicologia da educação com as fases de aprendizagem das crianças. Em Políticas Educacionais estudei a $L D B$ com o seu processo histórico e a importância do PPP. Na específica de matemática tive uma revisão dos conteúdos do ensino fundamental e ensino médio. $E$ entre outros conhecimentos adquiridos que foram de fundamental importância para a minha vida acadêmica. (Discente 16).

A introdução da Língua Brasileira de Sinais (LIBRAS) incluída no currículo por determinação do Decreto $n^{0}$ 5.626, de 22 de dezembro de 2005, foi introduzida no Esquema I da URCA, assim como outras temáticas como a diversidade, a cidadania, os direitos humanos, o estudo da Lei 10.639/03, alterada pela Lei 11.645/08, que torna obrigatório o ensino da história e cultura afro-brasileira e africana em todas as escolas, públicas e particulares, do ensino fundamental até o ensino médio, dentre outros, que por vezes, são trabalhados como seminários temáticos a partir do entendimento de que a escola é uma instituição dinâmica, que deve atender às demandas de cada tempo/sociedade:

Aprendi muitas coisas durante o curso. Mas o principal foi a ter uma visão totalmente diferente sobre a área da educação, do quanto é uma área interessante e rica. (Discente 04).

O principal foi a capacidade de colocar me no lugar do próximo, e me ver no olhar do outro, também o ensinar foi o saber maravilhoso conseguir transferir o saber é maravilhoso. (Discente 08).

Melhorou comunicação com aluno. Ampliou conhecimentos para melhor avaliar o aluno. Entendi que o melhor professor é aquele que consegue transmitir ao aluno a magia do aprender. (Discente 12). 
Considerando o tempo de funcionamento do Esquema I da URCA, a sua abrangência territorial e os depoimentos colhidos via questionários, é possível afirmar que o curso impacta positivamente a região do Cariri, tanto nos aspectos socioeconômicos como pedagógicos, capacitando e movimentando sujeitos nos seus espaços sociais e educacionais.

Quando perguntados sobre o que mudariam no curso, das dezesseis respostas, sete não mudariam nada, se dizem plenamente satisfeitos com a estrutura, o apoio que recebem dos professores. Três abordaram os materiais, quanto à entrega e mudança de textos. Três abordaram a inclusão de disciplinas para tratar de novas metodologias digitais, o que já foi implementado na turma que está em funcionamento e deve concluir em 2021.1. Por fim, houve uma sugestão de substituir Psicologia e Filosofia por Antropologia e uma resposta que pediu "menos ênfase nas pedagogias de cunho marxista", o que pode estar atrelado às disputas atuais do campo político.

Entendemos que o curso em análise prima por trabalhar a formação com respeito e ética, privilegiando a construção de saberes para além do conteúdo formal, o que se configura como uma forma de resistência contra os poderes que buscam o aligeiramento de tempos para a formação e teimam em desmerecer a docência como uma prioridade.

De maneira geral é possível afirmar pelo olhar dos discentes que o Programa Especial de Formação Pedagógica da URCA tem feito/faz a diferença na vida profissional deles, tanto pela qualidade da formação que recebem como pela habilitação que os torna aptos a concorrerem a concursos públicos e atuar de forma legal nas escolas de Educação Básica, especificamente nos anos finais do Ensino Fundamental e no Ensino Médio.

\section{Considerações finais}

Iniciamos este texto considerando o campo da formação docente como uma seara fértil de discussões e reflexões, em meio a cenários políticos, econômicos e ideológicos em disputas. Ressaltamos que a promulgação da Lei de Diretrizes e Bases da Educação Nacional, n. 9394/1996, imprimiu a exigência de formação em nível superior para todos os professores da educação básica e isto, atrelado a outros fatores, aumentou a demanda por formação. Resultado: programas começaram a surgir por todo país, por vezes com qualidade duvidosa.

Historicamente, a formação de professores no Brasil representa um descaso de políticas públicas que a reestruturação do capital nos anos de 1990 tenta corrigir, não com 
objetivos pedagógicos, verdadeiramente democráticos, mas mercadológicos. É evidente que as fragilidades da formação não podem ser superadas com fórmulas mágicas e aligeiradas de propostas prontas em programas e projetos, os desafios são inúmeros e por mais que se pesquisem ainda não há antídotos para séculos de exclusão.

O ressurgimento do Programa Especial de Formação Pedagógica, Esquema I, nesse sentido, se apresenta como uma evidência da afirmação de que ao longo da história a formação profissional docente nunca foi tomada com a seriedade que esta requer.

A URCA recebeu a proposta com as devidas ressalvas e assim como a UECE, num primeiro momento em parceria, primou pela realização de uma formação que embora atendesse aos objetivos de um sistema educacional em colapso por uma falta real de professores devidamente habilitados, está baseada em valores humanos, éticos, democráticos, técnicos, científicos, no conjunto de "saberes necessários à prática educativa".

Identificamos com a aplicação dos questionários que o público do Esquema I escolhe viver a docência, seja por motivação econômica (para conseguir um emprego), e/ou pedagógica (para se tornar um profissional melhor), atreladas a outras, de crescimento individual e coletivo. O fato é que eles sabem o que procuram, já são profissionais, isso ajuda na permanência deles, e, podemos afirmar, mantém uma procura estável pelo programa a cada ano. Soma-se a isso o fato desses profissionais já possuírem conhecimentos específicos das áreas em que pretendem atuar na docência, faltando-lhes os conhecimentos pedagógicos sistematizados e a habilitação exigida na supracitada lei. A pesquisa mostrou que fazer o curso em si já melhora de forma considerável a atuação desses profissionais nos mais diversos espaços sociais, impactando positivamente o crescimento dos munícipios que abrangem o território da URCA.

Assim, concluímos que experiências pontuais, por vezes, mostram resultados positivos, e é neste sentido que defendemos este modelo de formação, da forma como é efetuado na URCA, por entendermos que o nosso público e os aspectos de desenvolvimento sociais e pedagógicos que apresentam, ao longo e depois da formação, justificam a sua existência até como forma de resistência, embora considerando as suas inúmeras limitações em meio ao cenário educacional do país.

Por fim, seria interessante perceber, comparativamente, como acontece o Programa Especial de Formação Pedagógica em outras IES, mas como mencionamos no texto, as pesquisas sobre o mesmo são quase inexistentes. 


\section{REFERÊNCIAS}

ALVES, F. C.; FIALHO, L. M. F.; LIMA, M. S. L. Formação em pesquisa para professores da educação básica. Revista Tempos e Espaços em Educação, São Cristóvão (SE), v. 11, p. 285, 2018. Disponível em: https://seer.ufs.br/index.php/revtee/index. Acesso em: 15 mar. 2020 .

BICCAS, M. S. Reforma Francisco Campos: estratégias de formação de professores e modernização da escola mineira (1927-1930). In: MIGUEL, M. E. B.; VIDAL, D. G.; ARAUJO, J. C. S. (Org.). Reformas educacionais: as manifestações da Escola Nova no Brasil (1920 e 1946). Campinas, SP: Autores Associados; Uberlândia, MG: EDUFU, 2011. (Coleção Memória da Educação)

BRANDENBURG, C.; PEREIRA, A. S. M.; FIALHO, L. M. F. Práticas reflexivas do professor reflexivo: experiências metodológicas entre duas docentes do ensino superior. Práticas Educativas, Memórias e Oralidades - Rev. Pemo, Fortaleza (CE), v. 1, p. 1-16, 2019. Disponível em: https://revistas.uece.br/index.php/revpemo/article/view/3527. Acesso em: 15 mar. 2020.

BRASIL, Lei n. 5.792 de 11 de agosto de 1971. Fixa Diretrizes e Bases para o ensino de $1^{\circ}$ e $2^{\circ}$ graus, e dá outras providências. Brasília, D.O.U. 12 de agosto de 1971.

BRASIL, Lei nr. 5.540 de 28 de novembro de 1968. Fixa normas de organização e funcionamento do ensino superior e sua articulação com a escola média, e dá outras providências. Brasilia, D.O.U. 29 de novembro de 1968.

BRASIL. Decreto-Lei n. 1.190, de 4 de abril de 1939. Dá organização à Faculdade Nacional de Filosofia. Rio de Janeiro, RJ, 06 abr. 1939. Disponível em:

https://www2.camara.leg.br/legin/fed/declei/1930-1939/decreto-lei-1190-4-abril-1939-

349241-publicacaooriginal-1-pe.html. Acesso em: 15 de março de 2020.

BRASIL. Lei n. 9.394, de 24 de dezembro de 1996. Estabelece as Diretrizes e Bases da Educação Nacional. Brasília, D.O.U. 26 dezembro de 1996.

BRASIL. Ministério da Educação. Parecer n. 4, de 11 de março de 1997. Proposta de resolução referente ao programa especial de formação de Professores para o $1^{\circ}$ e $2^{\circ}$ graus de ensino - Esquema I. Brasília, DF: MEC, 15 mar. 1997. Disponível em: http://portal.mec.gov.br/cne/arquivos/pdf/PNCP0497.pdf. Acesso em: 03 de jan. 2020.

BRASIL. Resolução CNE/CP n. 2, de 20 de dezembro de 2019. Define as Diretrizes Curriculares Nacionais para a Formação Inicial de Professores para a Educação Básica e institui a Base Nacional Comum para a Formação Inicial de Professores da Educação Básica (BNC-Formação). Brasília, DF, 15 abr. 2020. Disponível em:

http://portal.mec.gov.br/index.php?option $=$ com_docman\&view $=$ download\&alias $=135951$ rcp002-19\&category_slug=dezembro-2019-pdf\&Itemid=30192. Acesso em: 20 abr. 2020.

BRZEZINSKI, I. (Org). Pedagogia, pedagogos e formação de professores. Campinas, SP: Papirus, 1996. (Coleção Magistério, Formação e Trabalho Pedagógico) 
BRZEZINSKI, I. (Org.). LDB dez anos depois: reinterpretação sob diversos olhares. São Paulo, SP: Cortez, 2008.

CARNEIRO, M. A. LDB, leitura crítico-compreensiva, artigo a artigo. 17. ed. atual. ampl. Petrópolis, RJ: Vozes, 2010.

FIALHO, L. M. F. et al. O uso da história oral na narrativa da história da educação no Ceará. Práticas Educativas, Memórias e Oralidades - Rev. Pemo, Fortaleza (CE), v. 2, n. 1, p. 113, 2020. Disponível em: https://revistas.uece.br/index.php/revpemo/article/view/3505.

Acesso em: 9 abr. 2021.

FIALHO, L. M. F.; CARVALHO, S. O. C.; NASCIMENTO, L. B. Santos memórias de Maria Helena da Silva: licenciatura em Pedagogia em tempos de ditadura (19661970). Cadernos de Pesquisa, São Luís (MA), v. 28, p. 321-341, 2021. Disponível em: http://www.periodicoseletronicos.ufma.br/index.php/cadernosdepesquisa/article/view/ 14922. Acesso em: 05 mar. 2021.

FLORENCIO, L. R. S.; FIALHO, L. M. F.; ALMEIDA, N. R. O. Política de Formação de Professores: A ingerência dos Organismos Internacionais no Brasil a partir da década de 1990. Holos, Natal (RN), v. 5, p. 303-312, 2017. Disponível em: http://www2.ifrn.edu.br/ojs/index.php/HOLOS/article/view/5757. Acesso em: 05 mar. 2021.

FREIRE, P. Pedagogia da autonomia, saberes necessários à prática educativa. São Paulo, SP: Paz e Terra, 1997

GAIOSO, N. P. L. O fenômeno da evasão escolar na educação superior no Brasil. Relatório técnico. Pró-reitoria de Pós-graduação e Pesquisa, Universidade Católica de Brasília, 2005

GIL, A. C. Como elaborar projetos de pesquisa. 6. ed. São Paulo, SP: Atlas, 2019.

GONÇALVES, M. I. P. C. Programa especial de formação pedagógica na URCA: origem, construção e reconstrução. Dissertação (Mestrado Profissional em Educação) Centro de Educação, Universidade Regional do Cariri. Crato, CE. 89 p. 2020

MENDES, M. C. F.; FIALHO, L. M. F.; MACHADO, C. J. S. Argentina Pereira Gomes: disseminação de inovações didáticas na educação primária na década de 1930. Revista Diálogo Educacional, Curitiba (PR), v. 19, n. 61, p. 527-550, 2019. Disponível em: https://periodicos.pucpr.br/index.php/dialogoeducacional/article/viewFile/24959/23519 Acesso em: 9 abr. 2021.

SOUZA, R. F. História da Organização do Trabalho Escolar e do Currículo no século XX (Ensino Primário e Secundário no Brasil). São Paulo, SP: Cortez, 2018. v. 2.

TARDIF, M. Saberes docentes e formação profissional. 2. ed. Petrópolis, RJ: Vozes, 2002.

VASCONCELOS, J. G.; FIALHO, L. M. F.; LOPES, T. M. R. Educação e liberdade em Rousseau. Educação \& Formação, Fortaleza (CE), v. 3, p. 210-223, 2018. Disponível em: https://revistas.uece.br/index.php/redufor/article/view/278. Acesso em: 15 fev. 2020. 
ZABALA, A. A prática educativa: como ensinar. Porto Alegre, RS: Artmed, 1998.

\section{Como referenciar este artigo}

GONÇALVES, M. I. P. C.; NORONHA, I. L. A.; QUEIROZ, Z. F. Programa Especial de Formação Pedagógica, uma reflexão histórica. Revista Ibero-Americana de Estudos em Educação, Araraquara, v. 16, n. esp.3, p. 1629-1646, jun. 2021. e-ISSN: 1982-5587. DOI: https://doi.org/10.21723/riaee.v16iesp.3.15301

Submissão em: 05/02/2021

Revisões requeridas em: 30/03/2021

Aprovado em: $12 / 05 / 2021$

Publicado em: 01/06/2021 